\title{
El centro monumental de Yanhuitlán y su arquitectura: un proceso histórico y ritual
}

\author{
Alessia Frassani
}

El ensayo examina el proceso histórico que llevó a la creación del centro monumental de Santo Domingo Yanhuitlán durante el siglo XVI. Se presentan fuentes documentales y se explica la importancia de las estrategias adoptadas por los gobernantes indígenas no sólo en la adquisición y organización de los recursos económicos, sino en los rituales y celebraciones que llevaron a la creación del centro ceremonial que se conserva hasta la actualidad.

PALABRAS CLAVE:Yanhuitlán, conventos, arquitectura, traza urbana, procesiones

The Monumental Center of Yanhuitlán and its Architecture: A Historical and Ritual Process

This essay examines the historical process behind the construction of the monumental center in Santo Domingo Yanhuitlán in the $16^{\text {th }}$ century. Based on documentary sources, I explain the strategies adopted by indigenous rulers and their subjects to gather and organize not only the financial resources required in the construction of the complex, but also the public ceremonies that animated the newly-created center.

KEYWORDS:Yanhuitlán, monastery, architecture, urban design, processions

Alessia Frassani: Departamento de Arte, Universidad de los Andes, Bogotá, Colombia a.frassani224@uniandes.edu.co 
$\mathrm{E}$

129 de abril de cada año se celebra en el pue-

blo de Santo Domingo Yanhuitlán, en la Mixteca Oaxaqueña, una solemne ceremonia durante la cual la imagen sagrada de un Cristo crucificado - mejor conocida con el nombre de Divino Señor de Ayuxi- es llevada en una larga procesión desde la capilla de El Calvario, en el extremo norte del pueblo, hasta la iglesia principal de Santo Domingo (véase foto 1). La imagen permanece allí hasta el último fin de semana de mayo, periodo durante el cual el lugar se convierte en el centro de actividades religiosas, cívicas y sociales. Documentada desde el siglo XVI, esta celebración, conocida como la Mayordomía del Divino Señor de Ayuxi, conecta virtual y ritualmente varios puntos significativos del pueblo. El presente trabajo hace énfasis en el papel que jugaron el culto a esta imagen y otros en la configuración de la arquitectura y el diseño urbano de Yanhuitlán en los inicios de la Colonia, al tiempo que reconstruye la historia documental del conjunto monumental de Yanhuitlán. Se subrayan las complejas relaciones de interdependencia entre el pueblo y las comunidades aledañas, así como las implicaciones socioeconómicas y políticas de la obra. Como veremos, las condiciones materiales que incidieron en la producción del espacio urbano y los rituales que se repetían una y otra vez alrededor de los lugares de culto y a lo largo del pueblo refutan la noción de que la apariencia característicamente hispánica de Yanhuitlán es resultado exclusivo del proceso de hispanización de la comunidad.

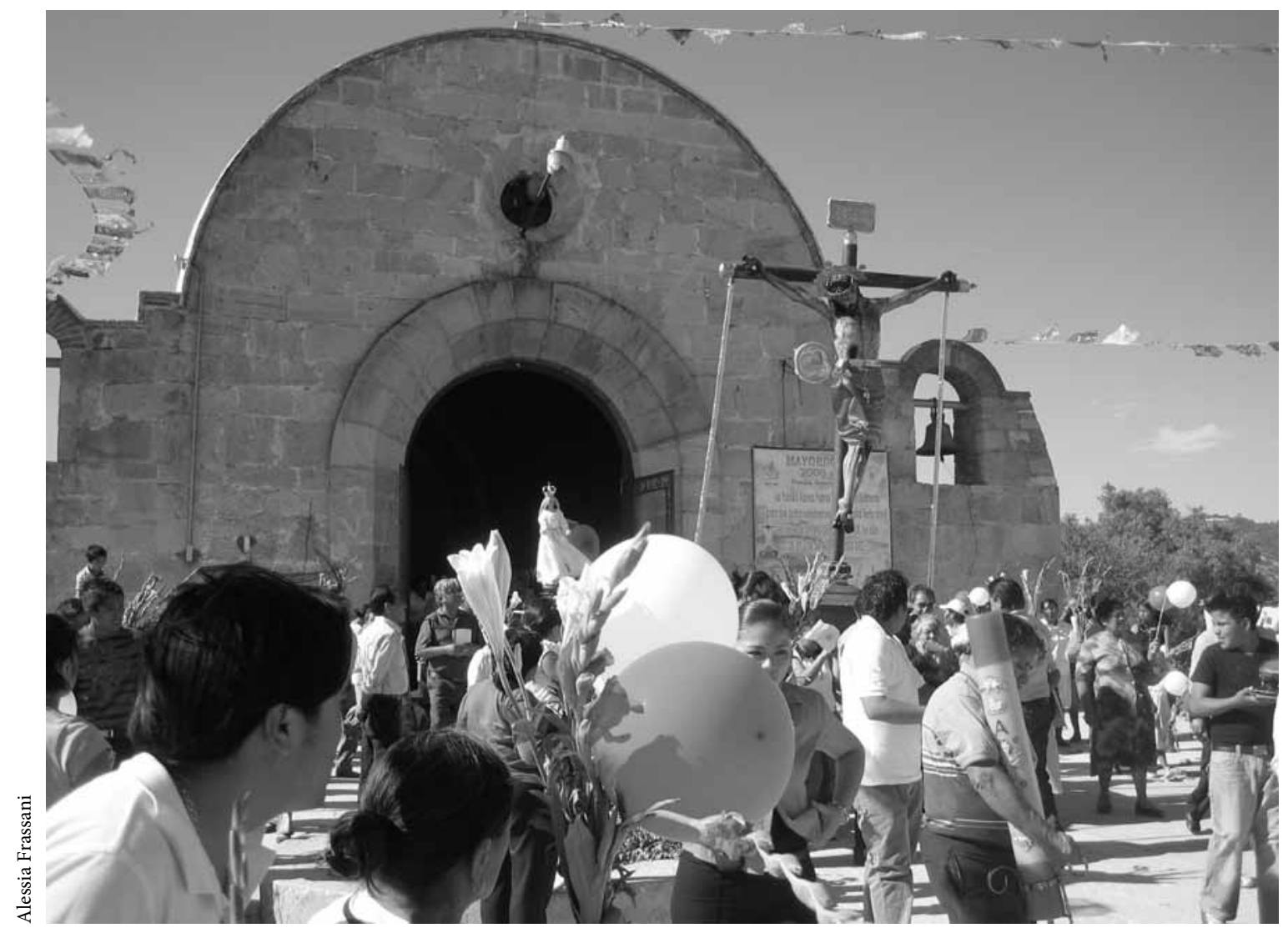

Foto 1. El Divino Señor de Ayuxi al ser sacado de la capilla de El Calvario durante la Mayordomía, Santo Domingo Yanhuitlán, Oaxaca, 2010. 


\section{LA CONSTRUCCIÓN DE LA IGLESIA}

Durante la época colonial el pueblo de Santo Domingo Yanhuitlán —entonces conocido por su nombre mixteco, Yodzocahi- fue heredero del cacicazgo de los Guzmanes, uno de los más importantes de la región -más tarde, de Pimentel y Villagómez-, que llegó a extenderse hasta la Mixteca Baja. ${ }^{1}$ Con el arribo de los españoles a la región, se constituyó la encomienda que fue otorgada por Hernán Cortés a su primo Francisco de las Casas en 1523 (Burgoa, 1934a: 290-291; Puga, 1945: 104). El asentamiento de frailes dominicos en los años cincuenta del siglo XVI, después de más de una década de disputas con los caciques y encomenderos locales, coincidió con los comienzos de los trabajos de erección de la iglesia y del convento, que constituyen hoy el centro monumental y ceremonial del pueblo. ${ }^{2}$ Construida entre 1550 y 1580, durante el apogeo de la expansión de las misiones españolas en Mesoamérica, la iglesia de Santo Domingo Yanhuitlán (véase foto 2) y su convento contiguo fueron de los asentamientos más importantes de los dominicos en la región mixteca. Aunque es imposible reconstruir acertadamente la cronología y las pautas de edificación del conjunto, varios documentos dispersos permiten hacerse una idea de las fases principales, actores, recursos y estrategias que fueron necesarios para concluir la obra. Si bien algunos documentos establecen la fundación del convento entre 1540 y 1541, los trabajos no parecen haber empezado sino hasta 1550 . Según las Actas capitulares de los dominicos, la casa de Yanhuitlán fue aceptada inicialmente en 1541, pero no se pobló definitivamente sino hasta 1548 (Vences, 1990: 124-134) debido a los conflictos surgidos por la oposición a la presencia dominica en el pueblo del cacique don Domingo de Guzmán, aliado del encomendero Francisco de las Casas.

\footnotetext{
${ }^{1}$ AGN, Civil, vol. 516; AGN, Tierras, vols. 400 y 986. Véase también Spores (1967: 155-188) y Chance (2008: 71-86).

${ }^{2}$ AGN, Inquisición, vol. 37, exp. 5, 7-10. Véase también la reconstrucción de Pérez Ortiz (2003).
}

No se habla entonces de trabajos de construcción en Yanhuitlán sino hasta 1550, cuando naturales del pueblo fueron atacados dentro de los límites del pueblo de Teposcolula mientras hacían calera y cortaban leña para la obra de la iglesia (Spores, 1992: 9). Ese mismo año se registró la residencia estable en el pueblo de frailes que ejercían su labor evangelizadora, como se deduce de una carta del virrey Antonio de Mendoza, en la que se ordena que se reparta al convento de Yanhuitlán la tercera parte de una limosna de ornamentos eclesiásticos donados al fraile Domingo de Betanzos (O’Gorman, 1939: 276-280). Según los documentos hallados, los trabajos de construcción se intensificaron durante el primer lustro de 1550. En 1552, por ejemplo, los naturales de Yanhuitlán pidieron permiso de nuevo para cortar 400 vigas de leña de los cerros de Jaltepec y Tamazola con el fin de continuar la obra del convento, mientras que la Corona entregó 200 pesos para financiarla (Gerhard, 1992: 522-523). También resultó fundamental el apoyo de pueblos cercanos sujetos a la cabecera de Yanhuitlán, que se vieron obligados a pagar prestaciones laborales que generaron protestas. Suchitepec, Mazaltepec, Coyotepec e Izquisuchitlán, como parte de la encomienda de Yanhuitlán, pagaron tributo a la cabecera para financiar la obra en construcción. Suchitepec, Amatlán y Axomulco prestaron hombres como mano de obra y recibieron la remuneración de un peso al día cada uno. ${ }^{3}$ En 1553, un número no especificado de pueblos intentaron separarse de la cabecera para librarse de la participación forzosa en los trabajos del convento (Gerhard, 1992: 523). Finalmente, en 1558 el convento de Yanhuitlán fue la sede del capítulo provincial de los dominicos, lo que podría indicar que la construcción se encontraba en las fases finales (Vences, 1990: 163). Parece que los trabajos en la iglesia culminaron en 1579, cuando el pintor y maestro de obra sevillano Andrés de Concha, quien residía en México desde 1568, construyó el retablo mayor (Ruiz, 1983; Spores, 1992: 65-66; Tovar de Teresa, 1992a: 83).

\footnotetext{
${ }^{3}$ Ayer, vol. 1211: ff. 107v-108r.
} 
Estos documentos no hablan sólo del impacto socioeconómico de los trabajos de construcción, sino también de sus implicaciones políticas: las autoridades indígenas de Yanhuitlán supieron aprovechar la preeminente posición del pueblo en el sistema de la encomienda española para extender y fortalecer su dominio en el marco de las relaciones indígenas, al reiterar su condición de cabecera entre los pueblos encomendados. Las financiaciones de los frailes que residían en el convento y las actividades litúrgicas que allí se desarrollaban resultaron de igual importancia. En 1562, el virrey Luis de Velasco ordenó que cada año se proporcionaran al convento 400 pesos, 80 fanegas de trigo y 100 fanegas de maíz para la manutención de los ocho frailes que, según el documento, residían normalmente en el monasterio. ${ }^{4}$ Ya en 1563 es claro que el convento ocupaba una posición preponderante en la economía local. En una carta enviada por Alonso Caballero, vecino español de Yanhuitlán, al visitador Valderrama se encuentran quejas sobre los lucrativos negocios de los frailes, involucrados en la venta de lana, cera, candelas y sombreros, producidos por vecinos del pueblo sin remuneración alguna de por medio (Scholes y Adams, 1961: 297-302). Además, se menciona que los frailes cobraban un tomín a cada persona que no acudiera a los trabajos de la iglesia, lo que era muy lucrativo porque muchos yanhuitecos eran mercaderes y no podían prestar servicio regularmente. Según Alonso Ca-ballero, fueron los frailes quienes persuadieron al cacique Gabriel de Guzmán para que construyera una suntuosa residencia cerca del convento con los mismos recursos utilizados para las obras de la iglesia.

En 1572, cuando los trabajos de construcción del convento debieron ya estar cerca de concluir, el pueblo de Tecomatlán, sujeto a Yanhuitlán, firmó un concierto para arreglar un pleito con la cabecera. ${ }^{5}$

\footnotetext{
${ }^{4}$ AGI, México, 68, R. 22, N. 65/7/1.

${ }^{5}$ AGI, Escribanía da Cámara, vol. 162C: ff. 283-285 y 363-364. Véase también la discusión de Hermann (2008).
}

Las dos partes decidieron, con la intermediación del encomendero Gonzalo de las Casas y del vicario fray Domingo de Aguiñaga, que de los 26 hombres al año que en ese momento acudían a los trabajos de la iglesia sólo fueran 10. Los naturales de Tecomatlán tampoco estaban de acuerdo con pagar una contribución para los gastos de las decoraciones de la iglesia, que con el concierto quedaron reducidas a flores "que se hallen en su distrito" para las celebraciones de la Pascua y Corpus Christi, en lugar de flores de vainilla, una costosa especie de orquídea. Más adelante se menciona que el pueblo sujeto estaba obligado a entregar tortillas, leña y zacate no sólo a la cabecera, sino también a los frailes del convento, tributo que también se redujo a la entrega obligatoria de leña para el convento. La alianza entre los frailes, los caciques y el encomendero fortaleció la posición estratégica de Yanhuitlán en la región mixteca y en el naciente sistema imperial español. Yanhuitlán fue uno de los centros más importantes de producción de seda —industria introducida por los españoles según los testimonios de los mismos frailes y encomenderos (Casas, 1996: 6; Burgoa, 1934a: 286)-. ${ }^{6}$ Mercaderes indígenas y españoles utilizaban a Yanhuitlán y su infraestructura en los comercios con Centro y Sudamérica. En 1550, los navíos que se embarcaban en Huatulco hacia Perú pasaban por Yanhuitlán, donde los tamemes locales eran ocupados con regularidad en las labores de carga (Spores, 1992: 11-13). Más tarde, en 1591, el cacique pidió a la Corona que se respetara un mandamiento de 1569 por medio del cual se obligaba a los pasajeros a permanecer en los aposentos del pueblo en la ruta de México y Los Ángeles a Oaxaca para pagar su estancia a las autoridades locales (Spores, 1992: 88-89).

\footnotetext{
6 Para una discusión, véase también Romero Frizzi (1996: 146-165).
} 


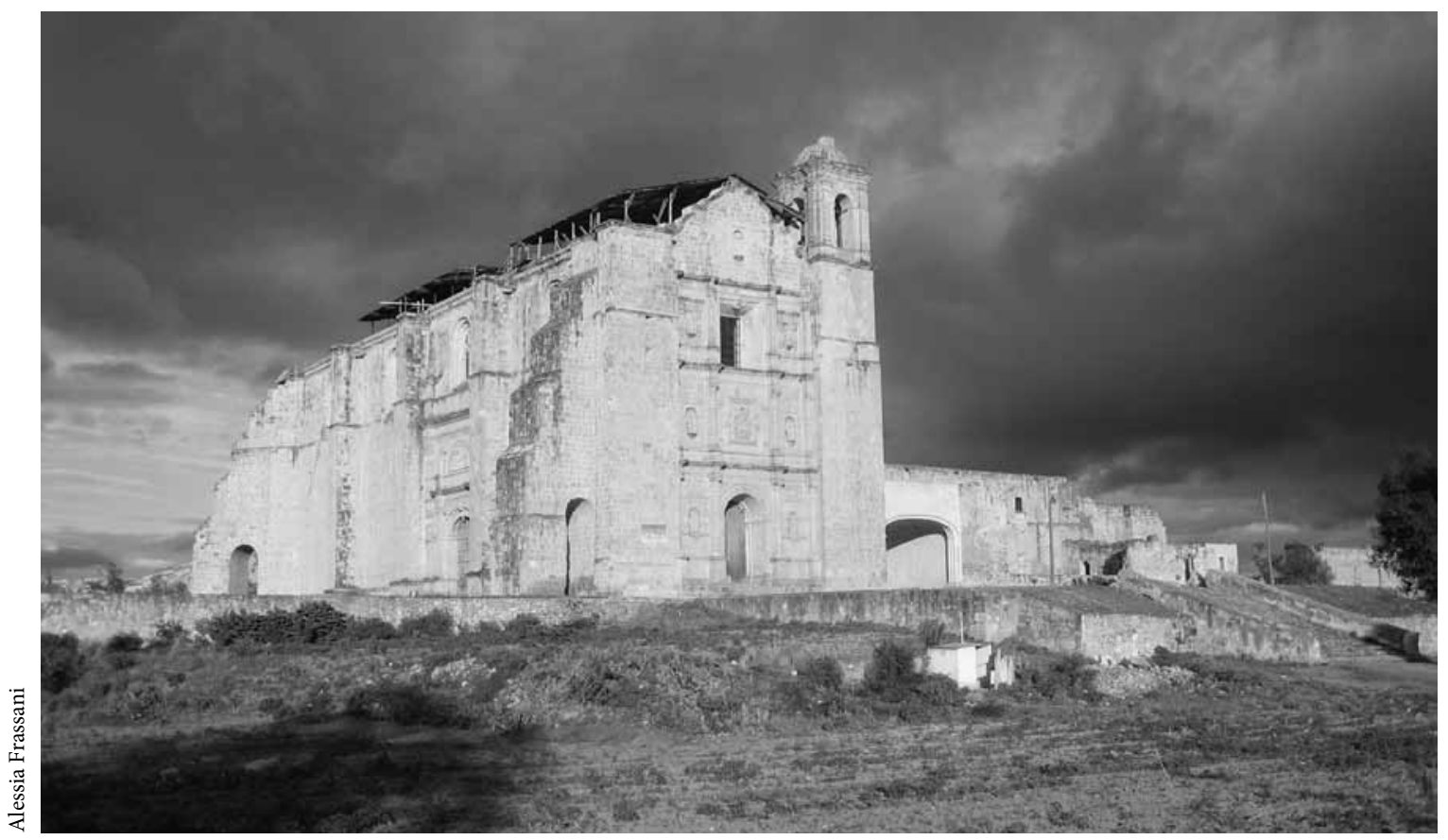

Foto 2. Iglesia y convento de Santo Domingo Yanhuitlán, Oaxaca, 2005.

\section{LA ARQUITECTURA MONUMENTAL Y EL TRAZO URBANO}

Esta breve reconstrucción del contexto histórico en el momento de la erección de la iglesia y del convento nos permite entender la arquitectura monumental yanhuiteca de la primera época colonial como la expresión de una ideología local que incorporó con éxito formas españolas dentro de un estilo de vida que siguió siendo fundamentalmente mixteco. La fachada de la iglesia de Santo Domingo en Yanhuitlán se caracteriza por dos grandes torres que no exceden la altura del cuerpo principal de la edificación y enmarcan un portal clásico compuesto por tres órdenes arquitectónicos. ${ }^{7} \mathrm{Al}$ igual que las iglesias

\footnotetext{
${ }^{7}$ La fachada presente no es la original (Brozon, 1978: 5-10). Estilísticamente la fachada-retablo presenta variaciones, sobre todo entre la parte superior -el último cuerpo y el remateque parece ser dieciochesca y las partes central e inferior que son muy parecidas a la fachada de Iglesia de Santo Domingo de la ciudad de Oaxaca.
}

contemporáneas de otras poblaciones de la región, como Teposcolula, Coixtlahuaca, Tamazulapan y Achiutla, la de Yanhuitlán presenta diferencias en relación con la fachada típica de las iglesias del centro de México. Como lo reconocen Kubler (1983: 291292) y McAndrew y Toussaint (1942: 320-321), mientras que las iglesias de las primeras misiones en el centro de México y en los actuales estados de Hidalgo, Morelos y Puebla tienen de manera característica una fachada de muros desnudos, con contrafuertes colocados diagonales en la esquina, decoraciones en la portada y remates almenados, en la región mixteca domina un diseño clásico. Lejos de ser un experimento aislado, la innovación mixteca es el prototipo de los diseños posteriores que se convertirían en el rasgo característico de la arquitectura religiosa de Oaxaca (Berlin, 1983: 47-66) en los siglos siguientes. Vargas Lugo (1966: 30), retomando una indicación de Kubler (1983: 292), define ese diseño como "clasicismo dominicano" y extiende su influencia hasta la provincia dominicana de Chiapas. 
A la articulación del estilo clásico de las fachadas mixtecas se le atribuye a menudo el término "fachada-retablo", debido a sus similitudes formales con los altares compuestos por varios paneles de las iglesias españolas e iberoamericanas. ${ }^{8}$ El altar principal del interior de la iglesia no sólo se refleja en el exterior, sino que las amplias fachadas establecen un sistema de ordenamiento que se extiende a todo el pueblo. La evidencia histórica y arqueológica muestra con claridad que la construcción de estos grandes complejos misioneros se realizó al mismo tiempo que otros importantes desarrollos urbanos. Entre los logros arquitectónicos más notables del periodo colonial temprano en los pueblos mixtecos están los palacios reales que combinaban funciones político-diplomáticas y residenciales, con lo cual continuaban la larga tradición mesoamericana de la arquitectura palaciega prehispánica. Los ejemplos más notables en Oaxaca pueden considerarse los palacios zapotecos de la época posclásica de Mitla y Yagul.

El palacio real mixteco, conocido como "aniñe", nectadas organizadas alrededor de patios internos. El aniñe mejor preservado y más conocido en la Mixteca se localiza en Teposcolula, donde se le conoce como "la Casa de la Cacica", en honor de doña Catalina, cacica de Teposcolula en la segunda mitad del siglo Xvi. ${ }^{9}$ Debajo del techo plano se extiende un friso característico compuesto por discos, que aparece frecuentemente asociado con la arquitectura prehispánica religiosa y de elite en documentos pictográficos (Kiracofe, 1995: 45-84). En contraste, los arcos redondos de la puerta de entrada son claramente una derivación europea. En Coixtlahuaca, la casa comunitaria muestra, a pesar de haber sufrido varias reconstrucciones, algunos rasgos — como el porche con arcadas de la plaza principal contiguo al atrio de la iglesia por el lado norte- que indican

\footnotetext{
${ }^{8} \mathrm{El}$ término fue acuñado en referencia a las portadas platerescas y clasicistas españolas (Chueca, 1953: 48, 97). Para el caso de Oaxaca, véase Berlin (1983: 49).

${ }^{9}$ AGN, Tierras, vol. 24, exp. 6, ff. 29-40.
}

que se trata de una construcción colonial. En Yanhuitlán, los vestigios de una construcción conocida como "la Casa del Cacique" hoy son parte de la sede del Comisariado de Bienes Comunales, que se sitúa a unas cuadras al sur del convento (véase foto 5 ). El padre jesuita Bernabé Cobo, quien pasó por el pueblo hacia 1630, confirma que la construcción de la residencia del gobernante y del convento se realizaron al mismo tiempo, con los mismos obreros y con la misma piedra. Según la descripción del padre, el complejo fue erigido en torno a un patio interno tan grande que también fue utilizado como plaza de toros. Las habitaciones en las que residía el gobernante estaban organizadas alrededor de dos patios más pequeños rodeados por columnas de piedra (Jiménez y Mateos, 1940: 49-50).

Cuando uno atraviesa los confines de los patios cerrados del aniñe, se hace evidente el diseño de mayor envergadura. En Teposcolula, Coixtlahuaca y en el mismo Yanhuitlán las residencias de los caciques, sede del poder gubernamental, son visibles desde los atrios de los conventos. La alineación de los dos complejos forma un eje que se proyecta a lo largo de líneas ortogonales y continúa al resto del pueblo. ${ }^{10}$ El propio convento no es sólo un edificio, sino una pieza del tejido urbano gracias al atrio (véase foto 3) que hace las veces de zona de transición entre los espacios cerrados del claustro y la iglesia y el resto del pueblo. Hacia 1670 el atrio de la iglesia de Yanhuitlán estaba enmarcado por muros de cinco varas de alto - alrededor de cuatro metros-, rematados por almenas (Burgoa, 1934a: 292). En Teposcolula y Coixtlahuaca estos muros todavía permanecen en pie, mientras que no se sabe cuándo se echaron abajo los muros en Yanhuitlán. Característicos de las misiones novohispanas, los atrios - que incluyen con frecuencia capillas abiertas y capilla-posas, como la de Coixtlahuaca- son rasgos originales de la arquitectura del Nuevo Mundo (McAndrew, 1965: 236-246). 10 Véase también el estudio de Kiracofe (1995) para el caso de
Teposcolula. 
Parece evidente que, aunque el convento fue construido encima de una antigua plataforma donde estaban enterrados los gobernantes locales y en la que se practicaban rituales en honor a los ancestros, el eje del complejo convento-aniñe (véase foto $4[1,2])$ creó un nuevo centro monumental: un lugar dedicado a las actividades religiosas y cívicas, en el que antes sólo había algunas construcciones dispersas. La existencia de una plataforma prehispánica es confirmada por varios testimonios durante el proceso inquisitorial contra los gobernantes de Yanhuitlán (Jiménez y Mateos, 1940: 40-42). Durante unas excavaciones hechas en 2010 para colocar una cisterna en el lado norte de la plataforma, yo misma pude ver lo que posiblemente era el antiguo suelo de la plataforma. La innovación estratégica de este diseño, que situaba el complejo en el centro de una extensa planicie rodeada de colinas densamente pobladas, fue revelada por un recorrido y por excavaciones estratigráficas realizadas en las inmediaciones y dentro de Yanhuitlán en la década de 1970 (Spores, 1972, 1974). Alrededor del convento y de las ruinas del palacio real colonial se descubrieron casi exclusivamente objetos de porcelana, utensilios metálicos, frascos de aceitunas y huesos de pollo - todos, elementos introducidos al Nuevo Mundo por los españoles-, en tanto que en las áreas vecinas sólo se encontró cerámica tradicional indígena con pintura roja sobre crema (Spores, 1974: 61-96). Esto indica que las nuevas actividades "hispánicas", indicios de las economías de consumo, prevalecían en el centro en contraste con las zonas periféricas, en donde se seguían practicando las antiguas costumbres.

Según una instrucción de Antonio de Mendoza a su sucesor, Luis de Velasco, justo antes de dejar el cargo en 1550, el virrey no estaba de acuerdo con la manera en que se habían llevado a cabo las obras arquitectónicas en Yanhuitlán hasta ese momento (Torre y Navarro, 1991: 115-116). Mendoza resaltaba que, aunque se estaba construyendo un gran templo, se habían desperdiciado importantes recursos debido a la falta de coordinación y supervisión adecuadas. El virrey hacía un comentario similar en relación con el complejo misionero de Teposcolula. Allí los frailes planeaban congregar a la población local indígena - que todavía habitaba en lo alto de las colinas- en un lugar muy húmedo en la parte llana, donde acababa de iniciar la construcción de una iglesia. Mendoza no aconsejaba la reubicación y solicitaba medidas para evitar que los frailes siguieran adelante con su plan.

Las anotaciones de Mendoza revelan cierto antagonismo entre los oficiales que representaban a la Corona española y los misioneros. En Yanhuitlán las autoridades indígenas se aliaron con estos últimos y buscaron el apoyo del encomendero local. El hecho de que la residencia real y el convento fueran construidos al mismo tiempo, pese al desacuerdo de Mendoza, es sólo una expresión de la capacidad de los caciques de Yanhuitlán de apropiarse de los lugares y de las instituciones "hispánicas" con el fin de garantizar la continuidad de la vida sociopolítica del pueblo. Mientras que el atrio era utilizado para instruir a los súbditos mixtecos sobre temas relacionados con los ancestros y el gobierno indígena, el aniñe servía como residencia de la familia gobernante y simultáneamente como "casa de la comunidad" - huahi tniño en mixteco, literalmente "casa del trabajo", que fray Francisco de Alvarado (1962) en su diccionario recopilado a finales del siglo XVI traduce como "cabildo" - para realizar las reuniones periódicas de los representantes de la República de Indios. ${ }^{11}$ Es decir que al mismo tiempo que la iglesia y la misa ofrecían la ocasión de reforzar el gobierno indígena, el escenario tradicional del palacio real acogía actividades derivadas de instituciones políticas introducidas por los españoles.

El virrey Mendoza tampoco estaba de acuerdo con el tema de la congregación, que obligaba a las poblaciones ubicadas en asentamientos dispersos a agruparse en un poblado centralizado y de mayor tamaño, una táctica aparentemente respaldada por

\footnotetext{
11 AgN, General de Parte, vol. 2, exp. 1053; AHJT, Sección
} Criminal, leg. 05, exp. 14; AGN, Tierras, vol. 400. 


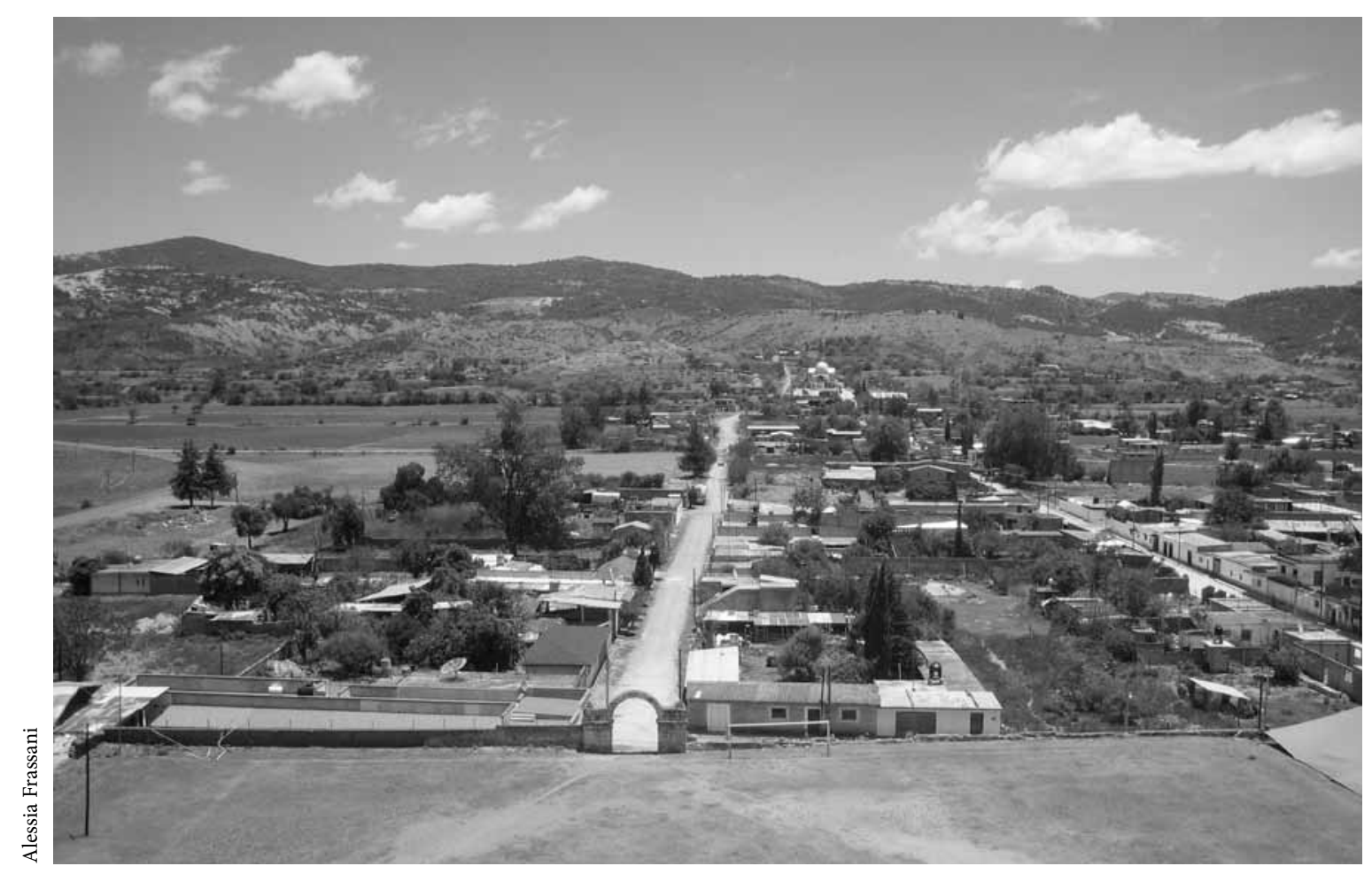

Foto 3. Atrio de la iglesia de Yanhuitlán. Al fondo se observa El Calvario y a la izquierda el antiguo sitio de Ayuxi, 2008.

los dominicos en Teposcolula (Torre y Navarro, 1991: 115; Spores y Robles, 2007: 333-353; y Zavala, 1982: 316-317). Con frecuencia y con razón se considera que las congregaciones llevadas a cabo en dos campañas distintas, 1551-1564 y 1598-1607, después de la promulgación de una serie de Cédulas Reales, constituyeron un gran impulso tras la reconfiguración de los asentamientos indígenas con el fin de adaptarse al modelo rural español (Cline, 1949; Zavala y Miranda, 1954: 56-66). Parece que en Yanhuitlán sólo ocurrió una congregación parcial después de 1598, que seguía en proceso en 1603, a pesar de la oposición del encomendero local y luego de más de 25 años de que hubiese concluido la construcción de la iglesia principal, el convento contiguo y el aniñe. ${ }^{12}$

\footnotetext{
12 AGN, Indios, vol. 6; Reales Cédulas, vol. 5, f. 150; Congregaciones, vol. 1 , exp. 1, ff. 1 y 36 .
}

En Yanhuitlán, el eje norte-sur que conecta el convento (véase foto 4 [1]) con el aniñe (véase foto 4 [2]) se extiende hacia el norte más allá del patio de la iglesia hasta alcanzar la Capilla de El Calvario, que alberga al Cristo de Ayuxi, una de las imágenes más veneradas en el valle (véanse fotos 4 [3] y 1). Según Burgoa (1934b: 346), en 1601 ya existía en el extremo norte del pueblo una capilla dedicada a la Santa Cruz - hoy Capilla de El Calvario-. Al oeste del pueblo, al otro lado de la Carretera Panamericana (véase foto 4 [5]) y en línea con el aniñe (véase foto 4 [2]), se llega a la Capilla de San Sebastián (véase foto 4 [4]), en construcción en $1606 \cdot{ }^{13}$ Por último, la plaza central del pueblo se halla hacia el este, detrás de la iglesia de Santo Domingo (véanse fotos 4 [6] y 5). Los registros indican que la plaza fue construida hacia 1598 , porque se refiere en relación con un

\footnotetext{
${ }^{13}$ AHJT, Sección Criminal, leg. 07, exp. 32, f. 4v.
} 
acueducto y una fuente pública que se edificaron en los alrededores (Zavala y Castelo, 1939, 6: 155156). La primera documentación acerca de edificios públicos importantes levantados en torno de la plaza data de 1643, cuando se mencionan unas casas reales en un testamento local. ${ }^{14}$ Podría plantearse como hipótesis que la construcción de las capillas de la Santa Cruz y de San Sebastián fuera una respuesta al impulso dado por la congregación de finales del siglo Xvi; sin embargo, ésta se estableció en torno al conjunto iglesia-convento-aniñe que había sido erigido unas décadas atrás.

A menudo se alude al supuesto interés del virrey Mendoza en las teorías urbanísticas del arquitecto e intelectual humanista italiano Leon Battista Alberti como un factor determinante en el desarrollo de los asentamientos y la arquitectura civil en Nueva España (Tovar de Teresa, 1992b). Si bien es cierto que el virrey poseía una copia del De Re Aedificatorial (Battista, [1550] 2007), las escasas y brevísimas sugerencias que Mendoza dejó en sus escritos, sobre todo en sus cartas y Mandamientos acerca de la adopción de una "traza moderada" en la fundación y planeación de los llamados "pueblos de indios", no permiten atribuir a la mente del virrey el diseño de cientos de asentamientos amerindios que fueron el resultado de una larga historia de adaptación a dramáticos cambios demográficos, ecológicos y económicos. Las palabras de Mendoza citadas arriba responden más a la actitud pragmática de un burócrata que a la visión utópica de un teórico. De igual manera, cabe señalar que las famosas Ordenanzas sobre descubrimiento, nueva población y pacificación de las Indias, firmadas por el rey Felipe II en 1573 y a menudo referidas como ejemplo tajante de la imposición de la política imperialista española en tierra americana, fueron escritas cuando la mayoría de las ciudades en el Nuevo

\footnotetext{
${ }^{14}$ AHJT, Sección Civil, leg. 14, exp. 73, f. 9r. Estos edificios reales sirvieron después como cárceles (AHJT, Sección Civil, leg. 15, exp. 36 , ff. $11 \mathrm{r}-11 \mathrm{v}$ ), función que mantuvieron hasta el siglo XIX, como lo atestigua una inscripción grabada en la entrada principal del edificio.
}

Mundo ya habían sido fundadas. Como anota Escobar (2007: 165-166), el asombro con el cual Cortés y Bernal Díaz del Castillo describieron el orden, la policía y la ornamentación de las ciudades del centro de México, consideradas por los conquistadores superiores a cualquier ciudad española de la época en cuanto a su eficiencia y capacidad de intercambios comerciales, sugieren el impacto que la experiencia urbanística precolombina tuvo en el desarrollo de los asentamientos ibéricos después de la Conquista española. De hecho, se podría argumentar que las Ordenanzas más bien reflejarían, una vez sistematizadas, las experimentaciones que se habían adelantado en Iberoamérica en las primeras décadas después del descubrimiento (Low, 1995: 748-762). Así que mientras algunos estudiosos postulan el damero colonial como la expresión del poder colonial en el continente por excelencia (Palm, 1951; Mundigo y Crouch, 1977: 247-248), otros reconocen en la plaza una de las principales contribuciones de la América antigua a la arquitectura y al urbanismo en el mundo hispánico (Gutiérrez, 1993; Chanfón, 1997). Lo que se plantea en este estudio es la importancia de algunos factores económicos, prácticas cotidianas y experiencias subjetivas - tal vez difíciles de recuperar, pero no por eso de menor relevancia- en la creación no sólo de la sociedad colonial, sino también de sus espacios materiales de actuación, lo que establece una diferencia con los enfoques que privilegian aspectos puramente teóricos del quehacer artístico y de sus desarrollos históricos.

Volviendo al caso de Yanhuitlán, resulta trascendental centrarse en los elementos específicos de su traza y su arquitectura, que denotan una apropiación local, histórica y geográfica de elementos que derivan de la tradición mixteca y de la española. Las transformaciones ocurridas durante el siglo XVI ofrecen un ejemplo sobresaliente para entender las complejas dinámicas entre las exigencias imperiales y las situaciones locales. En Yanhuitlán la supuesta "lógica colonial" del plano ortogonal entendida como la expresión de un poder externo impuesto 


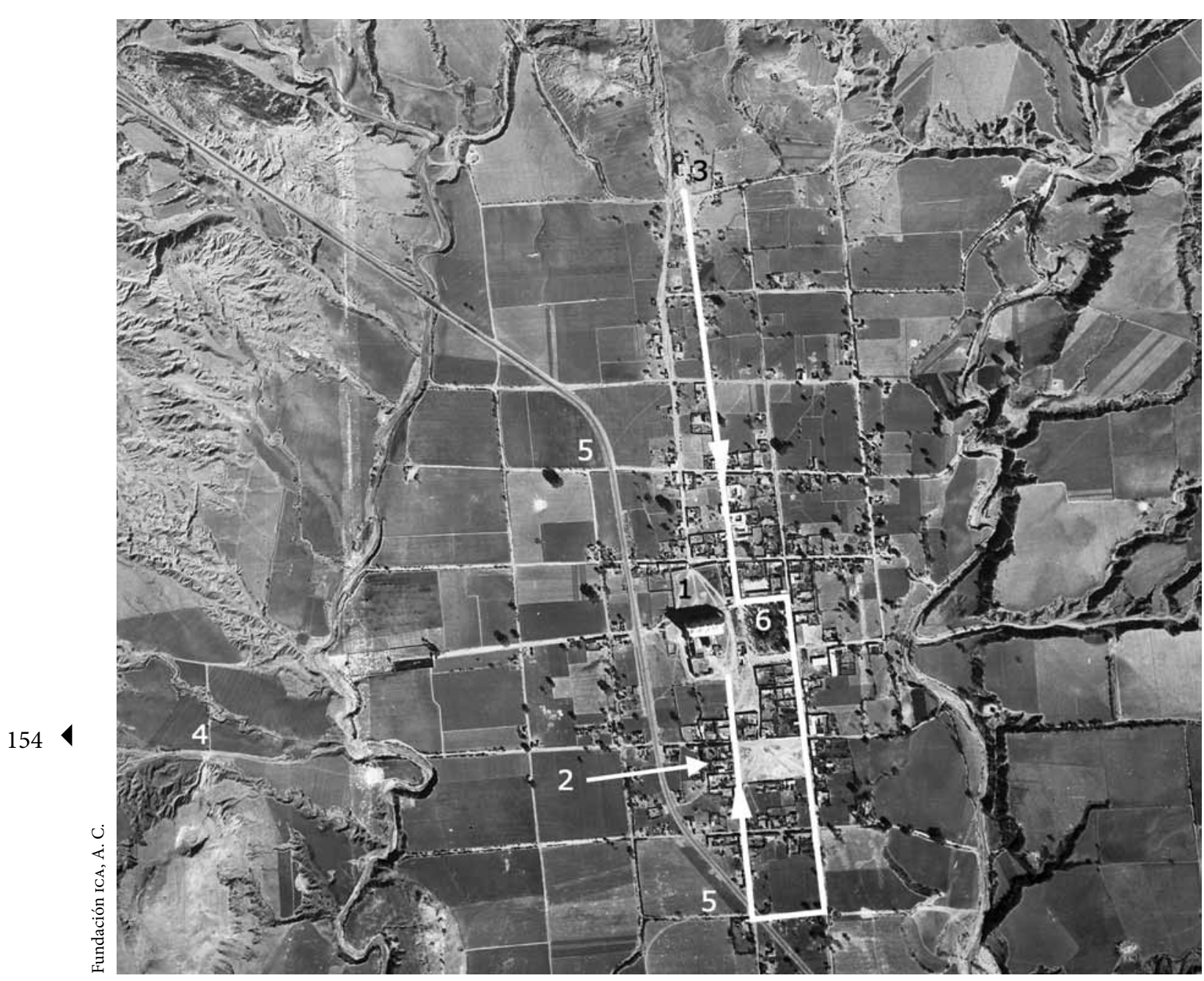

Foto 4. Fotografía aérea de Yanhuitlán: 1) Complejo del convento, 2) Aniñe, 3) El Calvario, 4) Capilla de San Sebastián, 5) Carretera Panamericana, 6) Plaza principal.

sobre un territorio conquistado se ve socavada por la ubicación trastocada de los monumentos más importantes (véase foto 5). Ciertos elementos del diseño arquitectónico y urbano del pueblo indican un compromiso claro y consciente con los desarrollos de las colonias españolas. ${ }^{15}$ Sin embargo, algunas variaciones significativas hablan de una libre apropiación de los rasgos del Renacimiento europeo,

${ }^{15}$ Véase por ejemplo la adopción de la fachada-retablo mencionada arriba. resultado de las estrategias locales de adaptación política y cultural al incipiente sistema imperial. Por ejemplo, la plaza principal era el principio generador clave en el diseño hispánico: el lugar donde se realizaban todas las actividades públicas, encarnadas en la iglesia y los edificios administrativos que la rodeaban. No obstante, en Yanhuitlán el área abierta más importante era el atrio, que se encuentra sobre la antigua plataforma elevada con el convento. El atrio como tal no está frente a la iglesia, sino al norte de ésta. La imponente elevación del lado norte de la 
iglesia ofrece el telón de fondo perfecto para las actividades ceremoniales y al mismo tiempo conecta este espacio con la Capilla de Ayuxi, que se halla en un lugar elevado claramente visible desde el atrio (véase foto 3). La sede del gobierno local, el aniñe, tampoco se localiza sobre la plaza principal, sino sobre el eje que une los dos referentes simbólicos por excelencia del valle: El Calvario y la iglesia (véase foto 4 [1-3]). Por último, la imponente fachada de la iglesia reclama más la atención de los viajeros y los transeúntes que de los residentes locales, en la medida en que está frente a la carretera en lugar de encontrarse en la plaza principal (véase foto 2). Conocida hoy como la Carretera Panamericana, esta vía era desde tiempos prehispánicos una importante ruta comercial en Mesoamérica y después de la Conquista y de la apertura del comercio marítimo con el Pacífico adquirió mayor preponderancia.

\section{EL PROCESO RITUAL: LITURGIA Y OBJETOS}

Si el plano ortogonal de Yanhuitlán no respondió a las formas coloniales de dominación, ¿qué fue entonces lo que moldeó la creación de este nuevo núcleo monumental? Con el fin de entender la lógica interna del cambio en la comunidad debemos observar las costumbres rituales y enfocarnos tanto en las creencias como en las conductas. Hemos visto que la construcción del convento y el aniñe en el valle no alteró de manera sustancial los modelos de poblamiento preexistentes, que se caracterizaban - todavía es así en algunas áreas- por un alto grado de dispersión. Aunque era una región densamente poblada en el periodo posclásico, no había una gran concentración urbana en la Mixteca, pues por lo general la gente vivía en poblados disgregados. Además, las actividades rituales se concentraban en pequeños altares regados por la zona y ubicados con mayor frecuencia en lo alto de las colinas. Los centros ceremoniales, que rara vez alcanzaban proporciones monumentales, no se encontraban en el centro de los poblados, sino alejados de éste (Spores, 1967: 96-98). La evidencia histórica muestra con claridad que Yanhuitlán comprendía varios barrios o siña - palabra en mixteco con la cual los barrios de Yanhuitlán se identifican en documentos coloniales- al menos desde la época posclásica y durante periodo colonial. ${ }^{16}$ Ayuxi, nombre con el que se denomina al venerado crucifijo de El Calvario, también era un prominente barrio cuya antigua localización en las colinas, a menos de un kilómetro y medio hacia el este de la capilla actual, se conoce todavía hoy. Otros siña importantes, Tinde y Ticoo, se situaban en lo alto de las colinas, detrás de la Capilla de San Sebastián. Aunque estos asentamientos están abandonados en la actualidad, constituían la división dominante del pueblo aún en 1783, según consta en una Relación de tributos. ${ }^{17}$ De acuerdo con el estudio realizado por Ronald Spores (1972: 88, 91), lo único que se halló en los lugares de Ayuxi y San Sebastián fueron objetos de cerámica con pintura roja sobre fondo crema, hecho que certifica la persistencia de los antiguos modelos de creencias y de conducta social cuando ya estaba bien avanzado el periodo colonial. Estas capillas parecen haber sido ubicadas a medio camino entre los antiguos asentamientos y el nuevo centro ceremonial y políticoadministrativo (véase foto $4[3,4]$ ). A nivel simbólico y funcional, estas capillas fueron el canal por medio del cual las instituciones españolas entraron y se incorporaron en el estilo de vida mixteco, hecho que podría haberse concretado con la congregación de finales del siglo XVI, como se mencionaba arriba. Según oí muchas veces, se cree que existe un pasaje subterráneo que conecta la Capilla de Ayuxi con la plataforma del convento. ${ }^{18}$ Este dato es importante, puesto que en la cosmología mesoamericana los pasajes subterráneos como cuevas y manantiales

\footnotetext{
${ }^{16}$ AGN, Civil, vol. 516; AGI, Escribanía da Cámara, leg. 162C, f. 307vta. Para una discusión de los barrios de Yanhuitlán, véase Terraciano (2001: 108-110)

${ }^{17}$ AHJT, Sección Civil, leg. 29, exp. 05-02, ff. 4r-9r.

${ }^{18}$ Conversación con los señores Gutiérrez Villanueva y Victorino Ramírez, Yanhuitlán, 2007.
} 
pueden significar un desplazamiento tanto a nivel físico como psicológico.

Pocos documentos del periodo colonial permiten hacer una reconstrucción general del uso de las imágenes y de los lugares sagrados en Yanhuitlán. En 1606, durante un juicio por un delito penal, un testigo declaró que algunos representantes de los pueblos que rodeaban a Yanhuitlán tomaron parte en las procesiones de Semana Santa, el Jueves y el Viernes Santo y el Domingo de Pascua, en las cuales desfilaron con sus propios crucifijos. ${ }^{19}$ Esta información indica que las obligaciones ceremoniales que implicaban la participación y el patrocinio de rituales comunitarios de los pueblos cercanos ya eran un aspecto relevante de las relaciones políticas entre pueblos, al menos desde comienzos del siglo XVII. No sólo las imágenes y sus cultos, sino también las capillas que las albergaban, parecen haber cumplido un propósito más allá de lo litúrgico. Funcionaban como edificios administrativos de los barrios, como consta en una petición de 1677 firmada por residentes naturales de Yanhuitlán, en la que solicitan permiso para terminar una capilla que resguardaba una imagen de Jesús Nazareno. ${ }^{20}$ El documento afirma que la edificación ha permanecido inconclusa a pesar de que la imagen es muy venerada en el pueblo y los alrededores y que la capilla misma ha sido usada durante años como casa de la comunidad. Por último, más de 30 años después, en 1711, varios representantes del barrio de Ayuxi declararon también que su imagen del Cristo Crucificado era muy venerada en su pueblo. En una serie de documentos entregados a un juez durante un caso por el asesinato de un mayordomo, se aseguraba que la mayordomía financiaba las celebraciones anuales de Corpus Christi, del Santo Cristo y

\footnotetext{
${ }^{19}$ AHJT, Sección Criminal, leg. 07, exp. 39. El pueblo que se menciona en el documento es Tocasahuala — hoy San Andrés Andúa-, el cual es uno de los 16 pueblos sometidos al gobierno de Yanhuitlán en una relación de 1550 (Jiménez y Mateos, 1940: 33). ${ }^{20}$ AGN, Indios, leg. 25, exp. 214, ff. 163-163v. La imagen de Jesús Nazareno representa por lo general a un Cristo cargando la Cruz.
}

de Semana Santa — se habla específicamente de la procesión nocturna del Jueves Santo, en la cual participaban flagelantes, conocida como la "Procesión de la Sangre" - . Los documentos aseveran que era costumbre que todos los barrios participaran en esta última procesión y llevaran su correspondiente crucifijo. ${ }^{21}$ Los crucifijos de diversos barrios que se conservan hoy en la sacristía de la iglesia hicieron parte de las procesiones de la Semana Santa por lo menos hasta los años cincuenta del siglo $\mathrm{xx}$ (Parmenter, 1964: 365-366). A mediados del siglo XVIII, algunos ángeles, también asociados a nombres de barrios, comenzaron a acompañar a los respectivos crucifijos durante las procesiones de Semana Santa, hasta que finalmente terminaron por reemplazarlos, como se observa en las celebraciones contemporáneas.

\section{LA MAYORDOMÍA DE AYUXI}

La importancia de los crucifijos y su devoción durante la Semana Santa y la mayordomía de Ayuxi no es de ninguna manera cosa del pasado. Aunque los crucifijos de los barrios ya no hacen parte de las procesiones de Semana Santa, el culto al Señor de Ayuxi es la principal celebración religiosa y cívica del valle. Comienza en los últimos días de abril y se extiende durante todo mayo. La mayordomía de Ayuxi se inscribe dentro de la extensa tradición mesoamericana de celebrar la Santa Cruz. En México, mayo coincide con el inicio de la temporada de lluvias y en las áreas rurales se intensifican las actividades ceremoniales propiciatorias, en las que los creyentes le ruegan a Dios que las cosechas sean buenas. En Malinaltepec, en el sureste guerrerense, la gente se reúne en lo alto de las montañas para dejar ofrendas en altares profusamente adornados en honor a la deidad de la lluvia, conocida hoy como San Marcos, cuya fiesta se celebra el 25 de abril (van

\footnotetext{
${ }^{21}$ AHJT, Sección Civil, leg. 20, exp. 9, ff. 3r-4r.
} 
der Loo, 1999: 212-218). En el pueblo nahua de Citlala se llevan los crucifijos de los barrios desde una capilla ubicada en lo alto de una colina hasta la iglesia principal, donde permanecen hasta el final de las celebraciones. A la cruz misma se le llama Tonantzin - "nuestra madre"- o Tonacaquahuitl — "el árbol de nuestro sustento"- (Broda, 2005: 233-237). En los días en que se celebra su culto las cruces quedan literalmente cubiertas de ofrendas de comida y flores, de manera similar al Señor de Ayuxi, que recibe numerosas canastas de frutas y flores. Aunque es un símbolo cristiano, en la América indígena la cruz está profundamente conectada con el concepto del árbol cósmico, el cual aparece con frecuencia en manuscritos pictográficos antiguos y en distintas fuentes de principios del periodo colonial (López Austin, 1997; McKeever, 1977: 183-226). En los tiempos antiguos se consideraba que, ubicados en las cuatro esquinas de la Tierra, los árboles eran los pilares que sostenían el cielo. Hoy las cruces marcan los límites de los pueblos y son símbolos duraderos de la soberanía de la comunidad. El crecimiento del árbol mismo está estrictamente conectado con la función regenerativa del sacrificio humano (Edgerton, 2001: 59-71). Desde los tiempos coloniales, la Santa Cruz cristiana ha adoptado el significado y la función del antiguo árbol cósmico al combinar el conocimiento cosmológico acerca del orden global con el significado ritual, por medio de la promulgación del sacrificio periódico de Jesús en la celebración de la misa (Marroquín, 1989: 42-49). Los antropólogos han examinado la cruz indígena en busca de claves acerca de la continuidad cultural y la supervivencia de creencias y rituales prehispánicos y señalan la asociación que existe entre la celebración de la Santa Cruz y los rituales de fertilidad y la planta de maíz en particular (Olivera, 1979: 143-156). El Divino Señor de Ayuxi de Yanhuitlán (véase foto 1) esconde bien sus antiguas raíces bajo una apariencia perfectamente española. La imagen hueca está hecha en parte de pasta de caña de maíz, una técnica mesoamericana que permitía la creación de esculturas ligeras y fáciles de transportar (Estrada, 1996; Noval

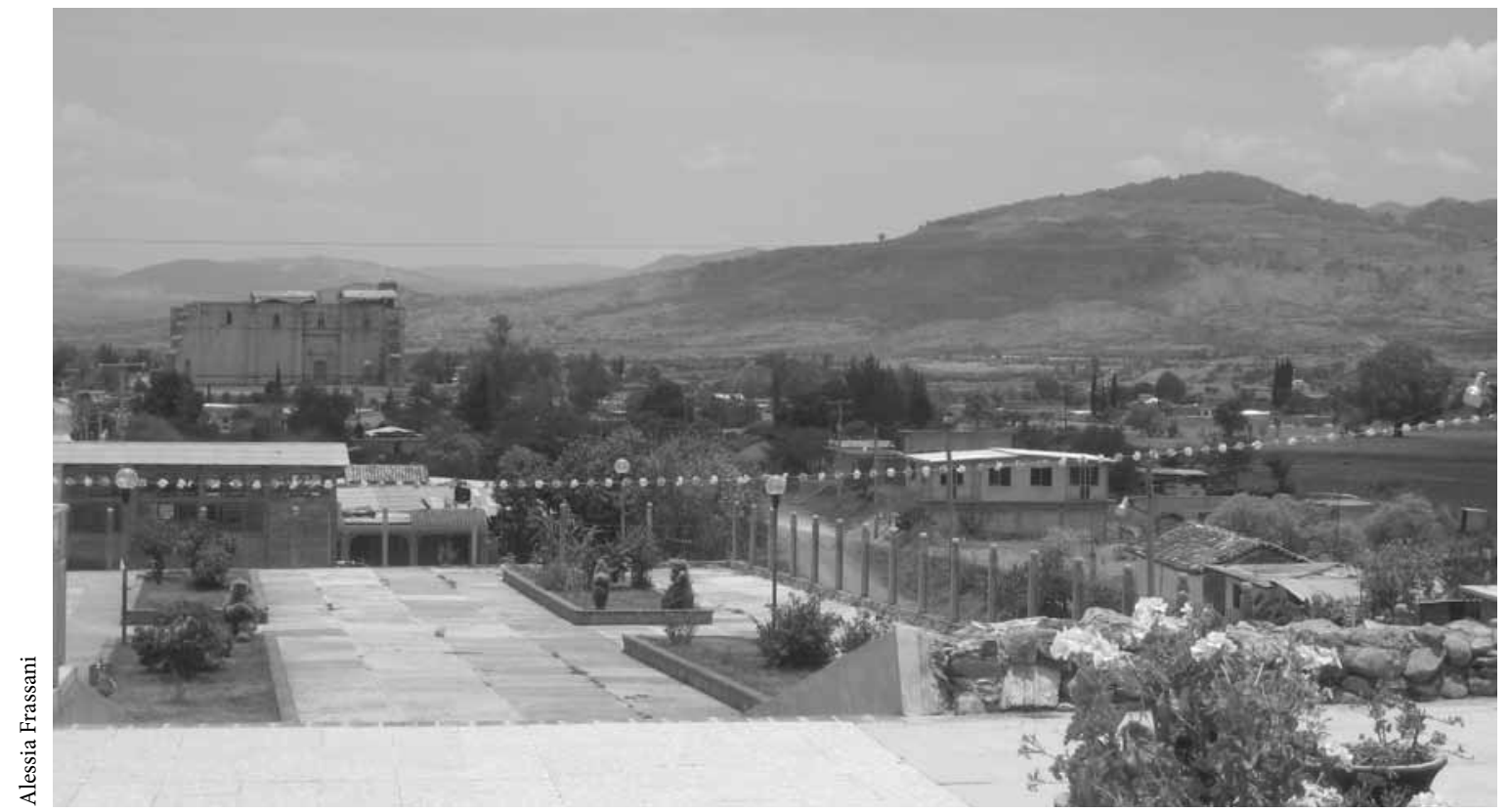

Foto 5. Vistos desde El Calvario: a la izquierda, el convento; a la derecha, el Cerro Jazmín, 2007. 
y Salazar, 2001: 225). El uso de un material derivado del maíz también otorga a la imagen un profundo significado metafórico relacionado con el ciclo de vida del alimento básico más importante de Mesoamérica. Durante una restauración realizada en 1997, se encontró en la cabeza del Cristo un documento escrito en lengua mixteca (Noval y Salazar, 2001: 227-229). El texto, de contenido religioso y litúrgico, no sólo menciona a la Santa Iglesia, sino los días festivos de la Cuaresma, el Viernes Santo y los domingos. Parte de un documento más extenso del cual fue extraído con mucho cuidado, el escrito mixteco puede ser una plegaria o una invocación, por el uso reiterado de paralelismos y repeticiones, elementos típicos del lenguaje ceremonial mesoamericano (Jansen, 1984).22

La ruta de la procesión de la mayordomía (véase foto 4) sigue un eje ceremonial que va de norte a sur, que centra y ordena idealmente a Yanhuitlán en torno al convento y a lo largo de algunos puntos significativos, entre los que se encuentran la plaza principal, la carretera y "la Casa del Cacique" - hoy sede del Comisariado de Bienes Comunales-. La procesión sigue una línea recta que se dirige hacia el sur desde El Calvario (véase foto 4 [3]) y atraviesa la plaza principal (véase foto 4 [6]) hasta alcanzar la Carretera Panamericana (véase foto 4 [5]). En este punto cambia de dirección en un ángulo de $180^{\circ}$ y pasa frente al aniñe (véase foto 4 [2]), hasta llegar a la iglesia, desde el sur, y al final da la vuelta al atrio (véase foto 4 [1]), para entrar a la iglesia por la puerta occidental. Vista en un contexto más amplio, esa ruta se inserta sobre un eje que contiene y conecta visualmente el Cerro Jazmín y el antiguo sitio de Ayuxi, dos lugares del periodo clásico que siguieron siendo visitados de manera ritual durante la época posclásica y la colonial (Spores, 1972: 86-87, 91) (véase foto 5). En toda Mesoamérica, los sitios del periodo clásico, como Teotihuacán en la Cuenca de México y Monte Albán en los Valles Centrales de

${ }^{22}$ Interpretación preliminar hecha por la autora y Michael Swanton.
Oaxaca, se convirtieron en lugares de adoración de los ancestros durante la época posclásica, lo que muestra que el pasado clásico fue reconocido y celebrado durante el periodo siguiente. La inscripción del pueblo colonial de Yanhuitlán dentro de esos referentes geográficos demuestra, de nuevo, los esfuerzos conscientes de sus antiguos habitantes por mantener la continuidad con el pasado, al tiempo que reconocían el comienzo de una nueva época. Mientras que los recuerdos y los relatos de los yanhuitecos son un indicio del aspecto sagrado que encierran los alrededores del pueblo, su iglesia y sus capillas, el complejo aniñe-convento - resultado de ajustes posteriores a la Conquista española- representa la materialización de una práctica espacial que comprendía actividades tanto religiosas como políticas: las reuniones en la iglesia para cumplir funciones sagradas y en el aniñe, para las sesiones del cabildo. Por último, la ruta ceremonial santifica estas prácticas rutinarias al permitir la apropiación simbólica del nuevo orden religioso y político que se reafirma desde entonces continuamente cada vez que tiene lugar una procesión. De manera similar, la arquitectura, el diseño urbano y la escultura coloniales tempranos se impusieron sobre el Yanhuitlán mixteco en un espacio de rituales, organización social y políticas locales de vieja data. Lo que creó la apariencia moderna de este pueblo y sus actividades religiosas no fue un concepto abstracto de dominación imperial. Por el contrario, nos vemos forzados a preguntarnos cuánto de lo que en la actualidad se percibe como prueba del carácter hispánico en el arte y la religiosidad latinoamericanos se debe, en realidad, a experimentaciones indígenas.

\section{BIBLIOGRAFÍA}

Alvarado, Francisco de y Wigberto Jiménez Moreno, [1593] 1962, Vocabulario en lengua mixteca, Instituto Nacional Indigenista, México.

Battista Alberti, León, [1550] 2007, De Re Aedificatoria, Ediciones Akal, Madrid. 
Berlin, Heinrich, 1983, "Oaxaca: la iglesia de San Felipe Neri”, en Archivo Español de Arte, vol. LVI, núm. 221, pp. 47-66.

Broda, Johanna, 2005, "La Fiesta de la Santa Cruz entre los nahuas de México: préstamo intercultural y tradición mesoamericana", en Antonio Garrido Aranda (ed.), El mundo festivo en España y América, Universidad de Córdoba, Excmo. Ayuntamiento de Montilla, Córdoba.

Brozon McDonald, Luis, 1978, "La primitiva portada de la iglesia del Convento de Santo Domingo Yanhuitlán, Oaxaca”, en Monumentos Históricos: Boletín, vol.1, pp. 5-10.

Burgoa, Francisco de, [1674] 1934a, Geográfica descripción, Talleres Gráficos de la Nación, México. —, [1674] 1934b, Palestra historial, Talleres Gráficos de la Nación, México.

Casas, Gonzalo de las, 1996, Arte nuevo para criar seda, Universidad de Granada, España.

Chance, John, 2008, "Alianzas matrimoniales coloniales entre caciques mixtecos: el caso de Acatlán-Petlalcingo", en Anuario de Estudios Americanos, vol. 65, núm. 1, pp. 71-86.

Chanfón Olmos, Carlos, 1997, Historia de la arquitectura y el urbanismo mexicanos, vol. 2, t. 1, Fondo de Cultura Económica, México.

Chueca Goitia, Fernando, 1953, Ars Hispaniae: arquitectura del siglo XVI, vol. 11, Plus-Ultra, Madrid.

Cline, Howard F., 1949, "Civil Congregations of the Indians in New Spain, 1598-1606", en The Hispanic American Historical Review, vol. 3, núm. 29, pp. 349-369.

Edgerton, Samuel Y., 2001, Theaters of Conversion: Religious Architecture and Indian Artisans in Colonial Mexico, University of New Mexico Press, Albuquerque.

Escobar, Jesús R., 2007, La Plaza Mayor y los orígenes del Madrid barroco, Nerea, Madrid.

Estrada Jasso, Andrés, 1996, Imágenes en caña de maíz, Universidad Autónoma de San Luis Potosí, México.

Gerhard, Peter, 1992, Síntesis e índice de los mandamientos virreinales, 1548-1553, Instituto de Investigaciones Históricas-Universidad Nacional Autónoma de México, México.

Gutiérrez, Ramón (ed.), 1993, Pueblos de indios: otro urbanismo en la región andina, Abya-Yala, Quito.

Hermann Lejarazu, Manuel, 2008, "Nuevas cabeceras contra viejos señoríos: la separación de Tecomatlán del señorío de Yanhuitlán”, en Anuario de Estudios Americanos, vol. 65, núm. 1, pp. 87-100.

Jansen, Maarten E. R. G. N., 1984, "Las lenguas divinas del México precolonial”, en Boletín de Estudios Latinoamericanos y del Caribe, núm. 38, pp. 3-14.
Jiménez Moreno, Wigberto y Salvador Mateos Higuera, 1940, Códice de Yanhuitlán, Museo Nacional, México.

Kiracofe, James B., 1995, "Architectural Fusion and Indigenous Ideology in Early Teposcolula: The Casa de la Cacica, a Building at the Edge of Oblivion", en Anales del Instituto de Investigaciones Estéticas, vol. XVII, núm. 66, pp. 45-84.

Kubler, George, 1983, Arquitectura mexicana del siglo XVI, Fondo de Cultura Económica, México.

López Austin, Alfredo, 1997, "El árbol cósmico en la tradición mesoamericana”, en Monografías del Jardín Botánico de Córdoba, vol. 5, pp. 85-98.

Low, Setha M., 1995, "Indigenous Architecture and the Spanish American Plaza in Mesoamerica and the Caribbean", en American Anthropologist, vol. 97, núm. 4, pp. 748-762.

Marroquín, Enrique, 1989, La cruz mesiánica: una aproximación al sincretismo católico indígena, Universidad Autónoma Benito Juárez de Oaxaca, Oaxaca.

McAndrew, John, 1965, The Open-air Churches of Sixteenth-century Mexico: Atrios, Posas, Open Chapels, and Other Studies, Harvard University Press, Cambridge.

_ y Manuel Toussaint, 1942, “Tecali, Zacatlán, and the 'Renacimiento Purista' in Mexico', en The Art Bulletin, vol. 24, núm. 4, pp. 311-325.

McKeever Furst, Jill Leslie, 1977, “The Tree Birth Tradition in the Mixteca, Mexico", en Journal of Latin American Lore, vol. 3, núm. 2, pp. 183-226.

Mundigo, Axel I. y Dora P. Crouch, 1977, “The City Planning Ordinances of the Laws of the Indies Revisited, Part I, Their Philosophy and Implications", en Town Planning Review, vol. 48, núm. 3, pp. 247-268.

Noval Vilar, Blanca y Francisco Javier Salazar Herrera, 2001, "La restauración de dos Cristos de pasta de caña como parte de los trabajos del proyecto de conservación integral en Santo Domingo Yanhuitlán, Oaxaca”, en Antonio F. García-Abásolo, Gabriela García Lascuráin y Joaquín Sánchez Ruiz (eds.), Imaginería indígena mexicana: una catequesis en caña de maíz, Publicaciones Obra Social y Cultural CajaSur, Córdoba, pp. 223-235.

O'Gorman, Edmundo, 1939, "Mandamientos del virrey don Antonio de Mendoza”, en Boletín del Archivo General de la Nación, vol. 10, pp. 213-311.

Olivera, Mercedes, 1979, "Huemitl de mayo en Citlala: ¿ofrenda para Chicomecoatl o para la Santa Cruz?”, en Barbro Dahlgren (ed.), Mesoamérica: homenaje para el doctor Paul Kirchhoff, Instituto Nacional de Antropología e Historia, México, pp. 143-156.

Palm, Erwin Walter, 1951, Los orígenes del urbanismo imperial en América, Instituto Panamericano de Geografía e Historia, Comisión de Historia, México. 
Parmenter, Ross, 1964, Week in Yanhuitlan, University of New Mexico Press, Albuquerque.

Pérez Ortiz, Alfonzo, 2003, Tierra de brumas: conflictos en la Mixteca Alta, 1523-1550, Plaza y Valdés, México.

Puga, Vasco de, [1525-1563] 1945, Prouisiones, cédulas, instrucciones de Su Magestad, Ediciones Cultura Hispánica, Madrid.

Romero Frizzi, María de los Ángeles, 1996, El sol y la cruz: los pueblos indios de Oaxaca colonial, Centro de Investigaciones y Estudios Superiores en Antropología Social, México.

Ruiz Gomar, José, 1983, “Noticias referentes al paso de algunos pintores a la Nueva España”, en Anales del Instituto de Investigaciones Estéticas, vol. XIV, núm. 53, pp. 65-73.

Scholes, France V. y Eleanor B. Adams (eds.), 1961, Cartas del licenciado Jerónimo Valderrama y otros documentos sobre su visita al gobierno de Nueva España, 15631565, Porrúa, México.

Spores, Ronald, 1967, The Mixtec Kings and their People, University of Oklahoma Press, Norman.

— 1972, An Archaeological Settlement Survey of the Nochixtlan Valley, Oaxaca, Vanderbilt University Publications in Anthropology, Nashville.

- 1974, Stratigraphic Excavations in the Nochixtlan Valley, Oaxaca, Vanderbilt University Publications in Anthropology, Nashville.

(ed.), 1992, Colección de documentos del Archivo General de la Nación para la etnohistoria de la Mixteca de Oaxaca en el siglo XVI, Vanderbilt University Publications in Anthropology, Nashville.

— y Nelly Robles García, 2007, "A Prehispanic (Postclassic) Capital Center in Colonial Transition", en Latin American Antiquity, vol. 18, núm. 3, pp. 333-353.

Terraciano, Kevin, 2001, The Mixtecs of Colonial Oaxaca: Nudzahui History, Sixteenth through Eighteenth Centuries, Stanford University Press, Stanford.

Torre Villar, Ernesto de la y Ramiro Navarro de Anda (eds.), 1991, Instrucciones y memorias de los virreyes novohispanos, Porrúa, México.
Tovar de Teresa, Guillermo, 1992a, Pintura y escultura en Nueva España (1557-1640), Grupo Azabache, México.

—_, 1992b, "La utopía del virrey Mendoza”, en Guillermo Tovar de Teresa, Miguel León-Portilla y Silvio Zavala, La utopía mexicana del siglo XvI: lo bello, lo verdadero y lo bueno, Grupo Azabache, México.

van der Loo, Peter, 1999, "Vamos a rezar a San Marcos", en David Carrasco (ed.), To Change Place: Aztec Ceremonial Landscapes, University Press of Colorado, Niwot, pp. 212-218.

Vargas Lugo, Elisa, 1966, "Las esculturas de la iglesia de San Pablo Guelatao", en Anales del Instituto de Investigaciones Estéticas, vol. IX, núm. 35, pp. 29-32.

Vences Vidal, Magdalena, 1990, "Fundaciones, aceptaciones y asignaciones en la provincia dominica de Santiago de México. Siglo xvi (primera parte)", en Archivo Dominicano, vol. 11, pp. 119-180.

Zavala, Silvio, 1982, Libros de asientos de la gobernación de la Nueva España: periodo del virrey Don Luis de Velasco, 1550-1552, Archivo General de la Nación, México. y María Castelo (eds.), 1939, Fuentes para la historia del trabajo en la Nueva España, 8 vols., Fondo de Cultura Económica, México.

— y José Miranda, 1954, "Instituciones indígenas en la Colonia", en Alfonso Caso et al. (eds.), La política indigenista en México: métodos y resultados, Instituto Nacional Indigenista, México, pp. 29-112.

\section{ARCHIVOS CONSULTADOS}

Archivo General de Indias (AGI), Sevilla.

Archivo General de la Nación (AGN), México, D. F.

Archivo Histórico del Juzgado de Teposcolula (АНJT), Oaxaca.

Colección Ayer (Ayer), Newberry Library, Chicago. 